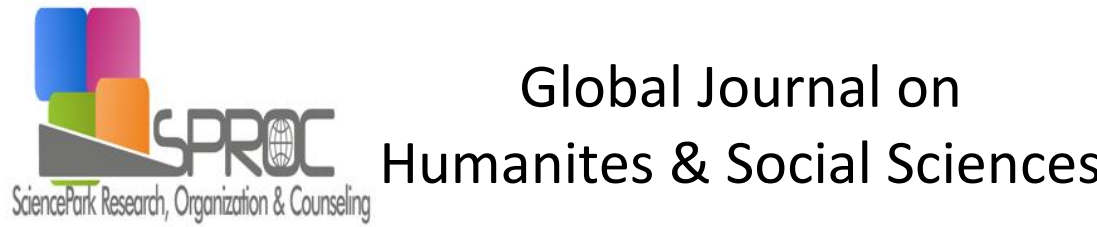

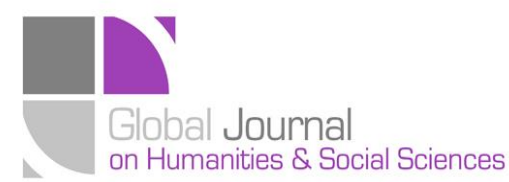

Vol 3 (2015) 510-518

Selected Paper of 4th World Conference on Design and Arts, (DAE-2015)

26-28 June 2015, St.Petersburg Christan University, St. Petersburg, Russia.

\section{Cultural patterns of shoe storage in the apartment life of İstanbul, a focus on the differences of shoe case usages}

Özgün Dilek *, Faculty of Architecture and Design, Department of Industrial Design, Anadolu University, Eskişehir 26470, Turkey

\section{Suggested Citation:}

Dilek, Ö. (2016). Cultural Patterns of shoe storage in the apartment life of İstanbul, a focus on the differences of shoe case usages, Global Journal on Humanites \& Social Sciences. [Online]. 03, pp 510-518. Available from: $\underline{\text { http://sproc.org/ojs/index.php/pntsbs }}$

Received January 10, 2015; revised March 03, 2015; accepted April 23, 2015.

Selection and peer review under responsibility of Prof. Dr. Milan Matijevic.

C2016 SciencePark Research, Organization \& Counseling. All rights reserved.

\begin{abstract}
This paper aims to reflect an ethnographic research on the usages of shoe cases in the apartment life of İstanbul. This topic is chosen to understand the effect of a cultural behaviour on taking off the shoes before entering a private place. This common cultural behaviour may have role on changing the design of shoe case, its variations developed by users and its artefacts. To do this research, I followed interviewing and literature review methods. Initially, I met people to talk about their habits on taking off the shoes and then I searched for the literature within the relation of common spaces in neighbourhood. The reason I followed that way is not to have some preconceptions though the literature before I conducted interviews. As a conclusion, paper inquiries the concept of borders, hygiene, and common place through the changing usages of a shoe case and through the habit of taking off the shoes.
\end{abstract}

Keywords: Shoe case, apartment life, borders, hygiene, common place

* ADDRESS FOR CORRESPONDENCE: Özgün Dilek, Department of Industrial Design, Faculty of Architecture and Design, Anadolu University, Eskişehir, 26470, Turkey. E-mail address: ozgundilek@anadolu.edu.tr 
Dilek, Ö. (2016). Cultural Patterns of shoe storage in the apartment life of İstanbul, a focus on the differences of shoe case usages, Global Journal on Humanites \& Social Sciences. [Online]. 03, pp 510-518. Available from: http://sproc.org/ojs/index.php/pntsbs

\section{Cultural Background}

In Turkey, general behaviour before entering the house is 'taking off the shoes'. This behaviour could also be observed before entering the Mosque as a 'house of God'. People prefer to cover the floor at home with the carpet and keep them clean. The relationship of the human body with the floor is closer than the other possibilities of modern life. The face touches on the floor during the pray and people are closer to the contamination while they are sitting and eating on the floor. Thus the floor needs to be clean and 'taking off the shoes' is one of the necessity to protect human body.

This closed relationship with the floor could be observed in Ottoman culture more often. The floor was mostly covered with carpets in the houses and prayers were laying their seccade ${ }^{*}$ on it (Faroqhi, 1998). Ottomans were not using dining tables with long legs but coming together around sofra ${ }^{\dagger}$. Instead of using chairs that will place them in higher position, they were sitting down on the carpets or mattresses while eating. From the writings of Faroqhi, we can understand that the relation of body with the floor was not limited by foot. Actions like sitting, eating, praying and sleeping was common to do on the floor. Those could be reason why people still prefer to remove their shoes while entering house in Turkey.

The behaviour of 'taking of shoes', was not supported with furniture that people can use as a shoe case in Ottoman culture. There were no heavy furniture at home. Even, beds were been laid down at night and were been gathered in big wardrobes in the morning. Having little furniture which is easy to transport was preferable in the Nomadic culture of Ottomans. Having gardens around houses was another factor that was giving chance to enlarge the personal space and to leave the shoes outside. The storage of shoes in vertical spaces or boxes was not required.

The change through the need for shoe case could be observed with the changes in the housing. Apartment life brought the idea of stowing in vertical levels within the limited spaces. In addition to this, living in a modern way offered different types of positioning on the floor. As Bourdieu (1977) mentions, modernization had an effect on redefining the movement of the body to reshape the habits of people to create new individualities.

We can follow those changes with two different theories of modernity according to Taylor (1999). The first is "acultural" theory which tries to melt all differences in one pot to achieve the great modern idea based on Westernization and rationalization. From this point of view everybody has to have similar behavioural patterns, taste and identities. If 'taking off the shoes' was interpreted as an essential behaviour and had been internalized in modern Turkish culture, we could map it in the "acultural" theory. The other approach is "cultural" modernity which defends the different cultural backgrounds having different results through modernization. "Alternative modernities" appear with the interaction of different cultures and with the immigration as we can observe so often in the city of istanbul. Since the shoe case usages in the apartment life of istanbul is affected by different cultural backgrounds, I will follow, "alternative modernities" approach to understand all those different improvisations.

When we focus on types of neighbourhood, we meet different relationships built in closed area. "Defended neighbourhood" refers to common culture and common identity neighbours brought from the past. Around gecekondu ${ }^{\ddagger}$ districts in the cities, this type of relationship is more common. People's expectation from this type of neighbourhood is developing good relationships and solidarity. (Ayata \& Ayata, 1996). People in the "community of limited liability" has more limited, specific interests for each other. Especially middle class, individualized and educated neighbourhood contributes that group. Roadways, shuttles, schools are shared interests for them and they prefer to see the common areas independent from the other's personal space.

\footnotetext{
* Kind of textile that people lays on the floor to pray on.

A round and short table enables people to eat around while they are sitting on the floor.

A type of fast-built house in one night without any related permission from the owner of the land or the government.
} 
The importance of neighbourhood appears with the usages of common areas. When people move to urban area, becoming an atomized piece of the society through loosing interaction via work is one of the way people live. Those people have less relationship with neighbours and they don't prefer to occupy shared places with their personal stuff (Ayata \& Ayata, 1996). Another type of city dwellers bring their community with them and keep their life in a small community rather than developing close relationship with new people. This type of living makes other's stuff acceptable on the shared surfaces with the consideration of others as a member of the community. (Ayata \& Ayata, 1996). Focusing on neighbours' interactions in common physical and social spaces could be eye-opening. (Migdal, 1997).As the examples below show how putting personal stuffs on the common areas would be unacceptable:

"I find it irritating to see shoes in front of the doors. It is primitive." (Interviewee 1)

"As an entity, shoes of neighbour on the common area disturbs me. Who are those villagers occupying common spaces? "(Interviewee 8)

The interviewees above have an acultural approach through defining a true type of behaviour. In that case, investigating the conflicts between neighbours and understanding the transition area between public and private is important. Interaction between different groups of people including the immigrants, city dwellers, villagers can vary in apartment life (Özyeğin, 2003) which has effect on the usages and placement of shoes case.

\section{Contemporary Behavior}

Through the interviews, general trends show the respect on the shared place usages in the apartment life. On the other hand when there is a chance to enlarge the personal space, people prefer to put their shoes out as in the example below:

"I live at the last level of the apartment. There is nobody except me living on that floor, so I use all the empty area on staircase for my needs. If there was someone living at the same floor, I wouldn't put my shoes there. (Interviewee 7)

Similarly, we can see the enlargement of the space in front of mosques especially during Friday pray. Putting shoes outside the door is possible to see when people have so many guests at their home. We can interpret leaving out the shoes in common place is a regular and acceptable type of behaviour in the culture. Special days that so many people come together, such as wedding, funeral or religious meeting at home is understandable by the neighbours. On the other hand, the opposite condition may appear as exampled below:

"Once, my neighbour downstairs had called their friends for Mevlüt to their place. The half of the level on staircase was full of shoes and it was unacceptable for me to see it. (Interviewee 1)" 
"Shoes outside of the door occupies the common area. It is visually bad. Not just because of the aesthetic reason but also because of the security I don't put them outside." (Interviewee 2)

"I am extremely negative about seeing the other's shoes on the stairs. Everybody has to take them in." (Interviewee 3)

The place of the action is equivocal. It could be inside of the house after closing the door or it could be outside just before opening the door. It is just in the intersection area of public and private life. The interaction of neighbours with a very personal stuff like shoes appears when people prefer to put their shoes outside of their personal place. For the place of shoe case what could be inspiring for designer is:

"I prefer to be without shoes at home, not because of hygiene but because of the comfort. A transition area that will act as a furniture may be more useful for the storage. (Interviewee 9)

Here, user match the idea of comfort with horizontal settling. The problem of borders become on surface when we have less horizontal space. The feeling of uncertainty and a need for a transition area for a dweller of the apartment is reflected below:

"In my opinion there is need for an interface between home and the rest of the apartment. There is always an anxiety about getting the place dirty. There is always a doubt where the border is to keep the home clean." (Interviewee 9)

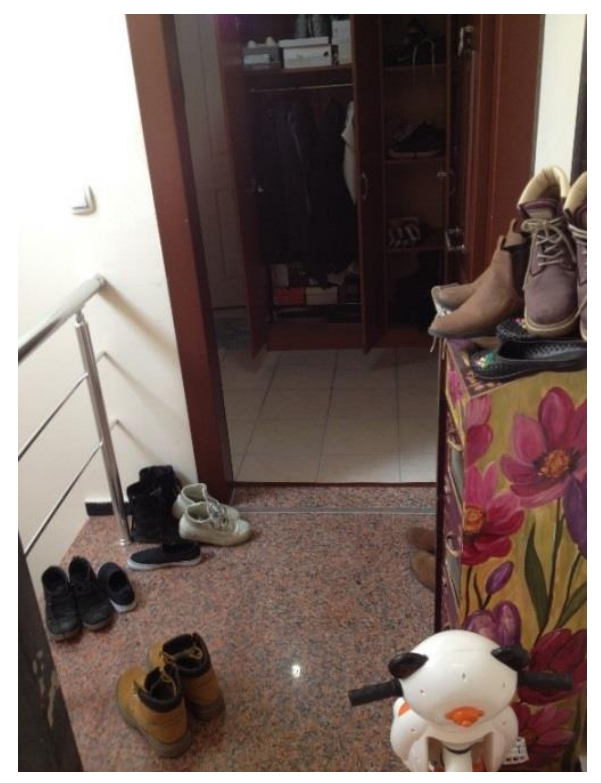

Figure 1. Out of the door of interviewee 7.

For some users, putting border line is preferable than having the intersection area between apartment and the home. The border starts with the' hygienic surfaces' that defines the place of the action outside. 
"I have to separate public and private life, so I ask people to take their shoes out behind the door and carry them until the shoe case inside." (Interviewee 1)

"Either inside or outside the house need to be clean. Both for visual, and hygienic reasons, it is good to leave the shoes outside of the door." (Interviewee 5)

"Streets are dirty in Turkey. I prefer to sit down, lay down on the carpet when I'm at home and for me it is not possible to enter home with the shoes for that reason." (Interviewee 2)
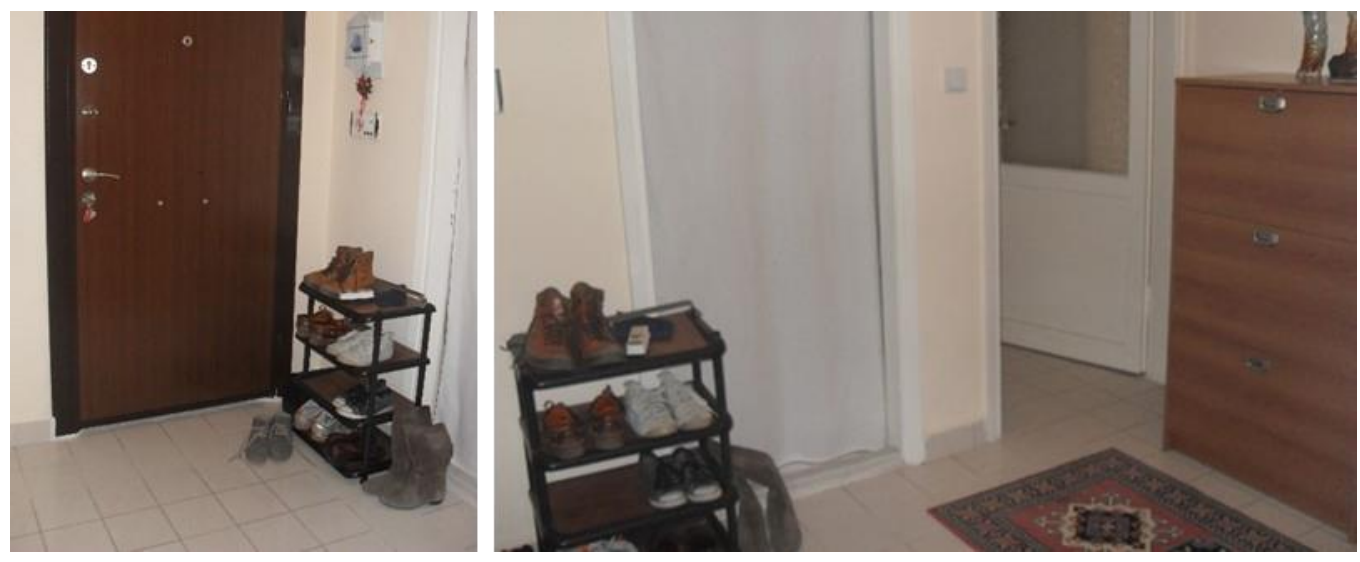

Figure 2. (a) Transition area between in and out; (b) An interface that is separated by carpet from the house of interviewee 9.

Storage of shoes is common problem for people who live in apartments. Some users prefer to use seasonal shoes in the closest area and the rest in the distant boxes which means there is a need for a place for unused shoes.

"After I take my shoes off I put them on the newspaper, I clean them and put in boxes. Seasonal shoes are on the shelves those are easy to reach. And the others are on higher or distant shelves." (Interviewee 2)

"I use my shoes so long about 10-15 years so when I have time I put them in the boxes to storage them in different place. On the other hand I have many empty boxes in the shoe case that I don't use in everyday life." (Interviewee 1) 


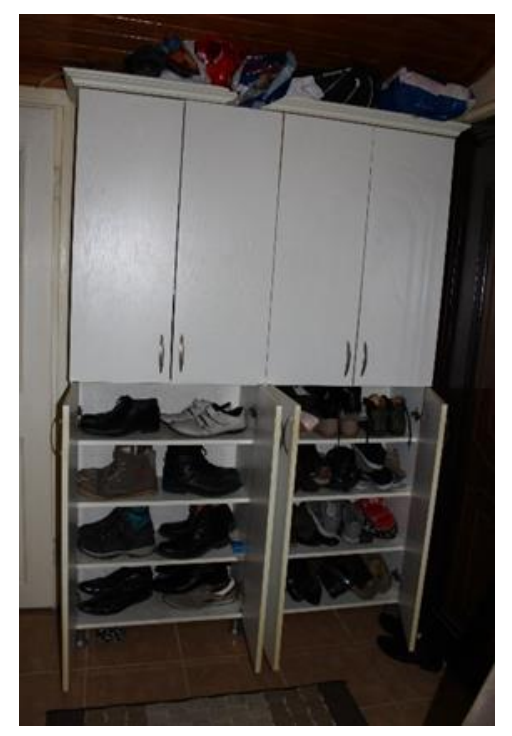

Figure 3. Shoe case of interviewee 5.

Organizing shoes in boxes could lead a disorder when they are just put in boxes. This problem is analyzed by a user and two different solution is created by functions and the conditions of the shoes as mentioned below:

"I prefer to leave the daily shoes out of the shoe case because it needs to get fresh air. So I organized two different cases. One of them is just near the entrance and the other one is on the opposite side to use when I need to store longer." (Interviewee 3)
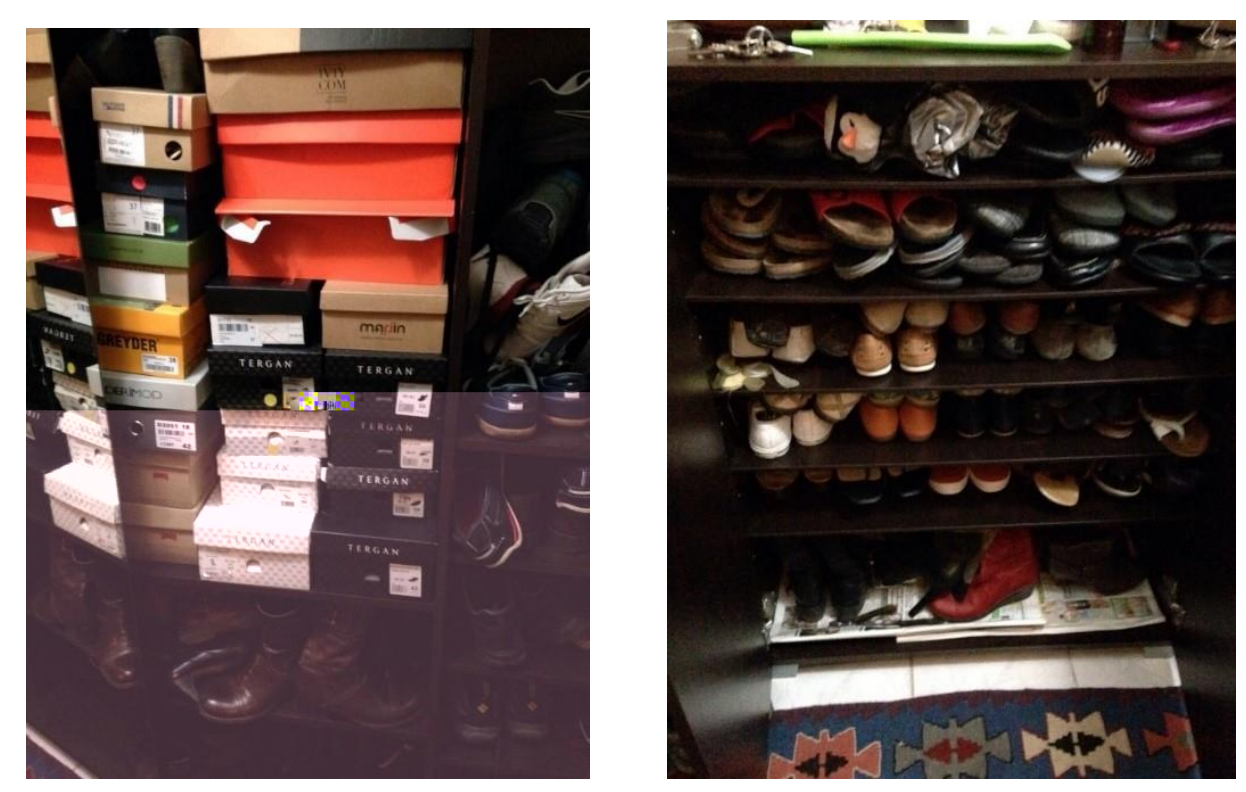

Figure 4. (a) Boxes in the shoe case of interviewee 1; (b) Shoe case of interviewee 1. 
Dilek, Ö. (2016). Cultural Patterns of shoe storage in the apartment life of istanbul, a focus on the differences of shoe case usages, Global Journal on Humanites \& Social Sciences. [On-72(i)7(h][([[(.)] TJETBT1 0 227.457.33 691.44 Tm[( )] TJETBT1 0 229.257.33 691.44 Tmc[】 0 03[( )] TJETBT1 0 237.417.3. 
"The concept of "apartment shoe" is just ugly because everyone gives this function after they decide it as the ugliest shoe of their life. No one wishes to steal them and they always occupy the stairs in an unaesthetic way." (Interviewee 2)

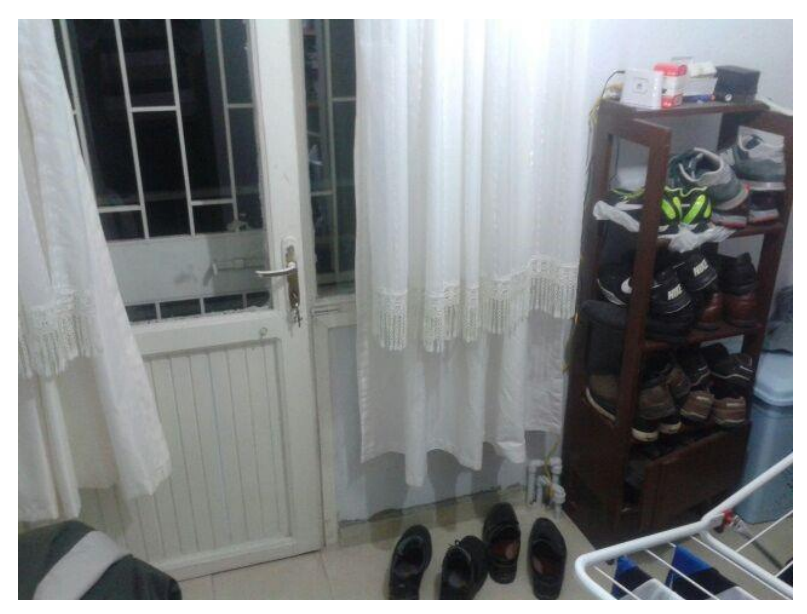

Figure 6. Shoe case of interviewee 6.

"We don't have an "apartment shoe" at our place even if we may need it to visit my aunt leaving one level down. I have never seen any shoe out of the doors in my apartment. The reason could be living with upper middle class neighbors." (Interviewee 4)

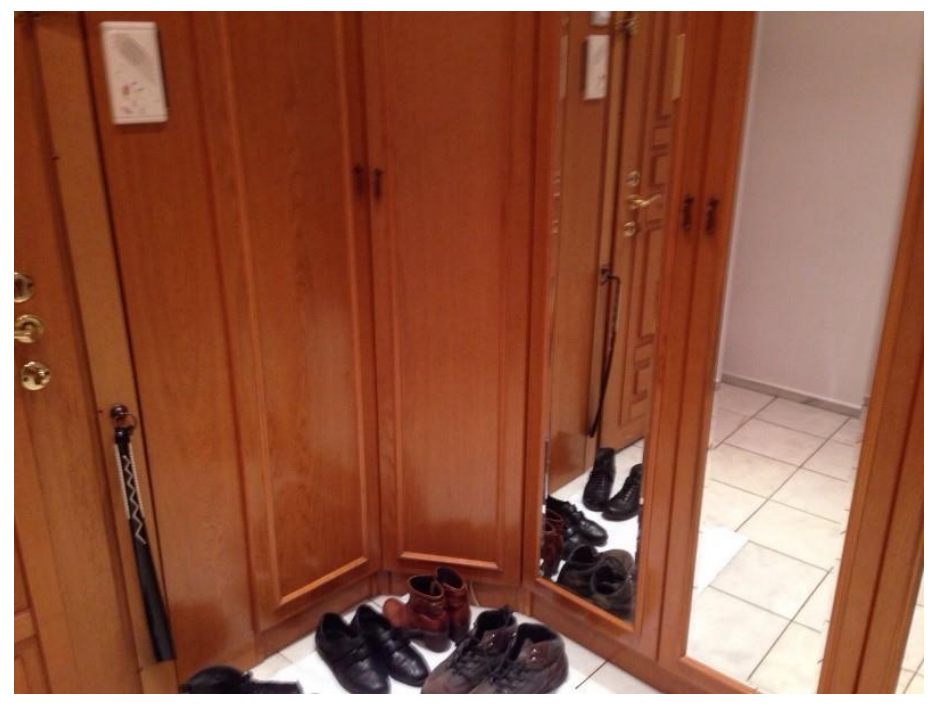

Figure 7. Shoe case of interviewee 4.

Another disordered situation appears in the times of hurry. The shoe case suddenly becomes eclectic and new layers are required for fast solutions.

"If I am in a hurry I prefer to enter in with the shoes and then put them on a newspaper." (Interviewee 2) 

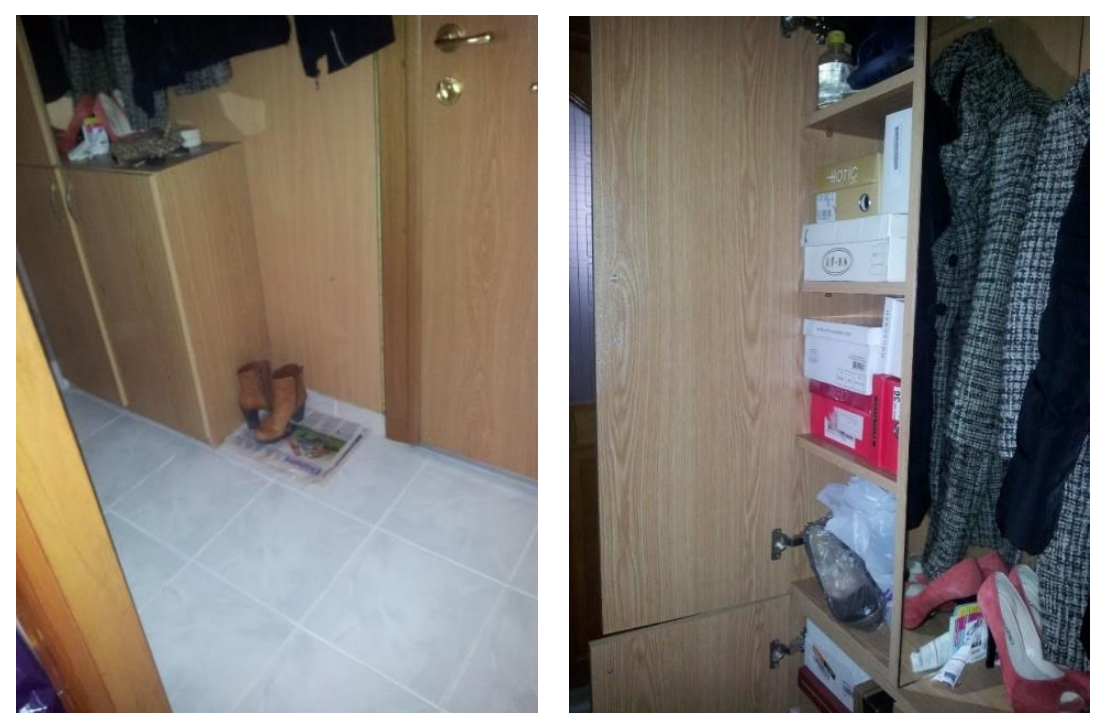

Figure 8. (a) Usage of newspaper as temporal and fast solution by interviewee 2; (b) Shoe case of interviewee 2.

\section{Conclusion:}

In this paper I analyzed the effect of a behavior 'taking off the shoes' before entering the private place through conducting interviews. Following this behavior, I came across with such inquires on public-private dilemma, borders, hygiene, common rules of apartment life and relation types of neighborhood. Shoe cases used in daily life and interviewees reflected how the behavior does not have certain shapes. This ambiguity could lead to define new types of function, meaning and behavior.

Looking from the design perspective, concepts could be developed through transition areas, exposition types, and different rhythm of the behavior. Shoe cases could be designed for public places and common usages. While doing that the cultural background and the routines of everyday life is important. Living in the apartment and changes on the needs of hygiene, has not enough effect on the cultural behavior of 'taking off shoes' which reflects a case of an alternative/cultural modernization.

\section{References}

Ayata, S., \& Ayata A.G. (1996). Konut, Komşuluk ve Kent Kültürü. Ankara : T.C.Başbakanlık Toplu Konut İdaresi Başkanlığı.

Bourdieu, P. (1977). Outline of a theory of practice. Cambridge: Cambridge University Press.

Faroqhi, Suraiya. (1998). Osmanlı Kültürü ve Gündelik Yaşam: Ortaçağdan Yirminci Yüzyıla. İstanbul: Tarih Vakfı.

Migdal, J. S. (1997). "Olgu ve Kurgunun Buluşma Zemini", (eds) S. Bozdoğan ve R. Kasaba in Türkiye'de Ulusallaşma ve Modern Kimlik. İstanbul: Tarih Vakfı Yurt Yayınları.

Özyegin, G. (2003). "Kapıcılar, Gündelikçiler ve Ev Sahipleri: Türk Kent Yaşamında Sorunlu Karşılaşmalar", (der) Deniz Kandiyoti, Ayse Saktanber in Kultur Fragmanlari/ Turkiye'de Gundelik Hayat. İstanbul: Metis.

Taylor, C. (1999). "Two Theories of Modernity." Public Culture: Society for Transnational Cultural Studies. Millenial Quartet, Volume 1: Alter/Native Modernities. Guest Ed. Dilip Parameshwar Goankar. Duke University Press. 